\title{
Reducing Environmental Risk by Applying a Polyvalent Model of Waste Management in the Restaurant Industry
}

\author{
Romulus Gruia ${ }^{1,2,3}$, Gabriel-Iustin Florescu ${ }^{1}$, Liviu Gaceu ${ }^{1,2,3}{ }^{\infty}$, Oana Bianca Oprea ${ }^{1, * \mathbb{C}}$ and Nicolae Ţane ${ }^{1}$ \\ 1 Faculty of Food and Tourism, Transilvania University of Brasov, 500036 Brasov, Romania; \\ ecotec@unitbv.ro (R.G.); iustin_gabrielflorescu@yahoo.com (G.-I.F.); gaceul@unitbv.ro (L.G.); \\ nictan54@unitbv.ro (N.T.) \\ 2 CSCBAS \&CE-MONT Centre, INCE-Romanian Academy, 023993 Bucharest, Romania \\ 3 Academy of Romanian Scientists, 050094 Bucharest, Romania \\ * Correspondence: oprea.oana.bianca@unitbv.ro; Tel.: +40-727-171-083
}

Citation: Gruia, R.; Florescu, G.-I.; Gaceu, L.; Oprea, O.B.; Ţane, N. Reducing Environmental Risk by Applying a Polyvalent Model of Waste Management in the Restaurant Industry. Sustainability 2021, 13, 5852. https://doi.org/10.3390/su13115852

Academic Editors: Anet Režek Jambrak and Ilija Djekic

Received: 22 April 2021

Accepted: 20 May 2021

Published: 23 May 2021

Publisher's Note: MDPI stays neutral with regard to jurisdictional claims in published maps and institutional affiliations.

Copyright: (c) 2021 by the authors. Licensee MDPI, Basel, Switzerland. This article is an open access article distributed under the terms and conditions of the Creative Commons Attribution (CC BY) license (https:// creativecommons.org/licenses/by/ $4.0 /)$.

\begin{abstract}
A series of concerns regarding the circular economy and linked to a responsible attitude toward environmental protection, have been approached in this paper. These represent essential demands in order for restaurants to be profitable and sustainable in the future. The cost of food wastes has been taken into consideration as a strategic problem in the restaurant logistic chain. A literature review shows that there is a lack of appropriate knowledge and technology in dealing with eco-waste management. The paper presents a functional polyvalent model of the logistic chain of a restaurant, represented in the form of interconnected processes covered by the flows of food goods and wastes in different stages and operations, having associated the flows of optimized costs. The application of the sustainable technology model and waste management system is illustrated by a case study from Brașov County, Romania. The research proves that applying the "polyvalent model of improvement of waste management practices" has positive effects concerning the possibilities of minimizing physical waste to reduce the volume of waste from restaurant activity, to reduce costs with waste elimination, and to create value-added, by reusing and recycling food raw materials. Results show that by applying the TEWAMA-R model to food preparation, the total amount of reused beef waste per month increased to $33.4 \%$ and the recycling of waste increased to $41.1 \%$ (given that all waste was disposed of in application of standard technology). The disposal was reduced from $100 \%$ to $25.5 \%$. The presented model allows for environmental impact reduction in the restaurant industry by reducing/eliminating waste or by-products that are carriers of huge resources of water and energy.
\end{abstract}

Keywords: food wastes; hospitality; management; restaurant

\section{Introduction}

\subsection{Environmental Risk in Restaurant Industry}

The EU environment programs aim to diminish resource use in relation to economic development. In the hospitality field, scientists have the responsibility to generate ideas and to create operational mechanisms useful to managers from restaurants in the direction of reducing the food wastes volume, which makes possible the efforts to diminish operational costs. They aim to increase the efficiency of restaurant activity, under the hypothesis that the volume of production and services from public food grows more than the cost of consumed resources and the cost of waste neutralization and generated emissions. This fact does not guarantee a pressure reduction upon the environment in absolute terms. Consequently, when estimating the sustainability of local restaurant systems, it is necessary to go beyond the simple measurement of the so-called "relative decoupling", that is, if the volume of provided food services increases faster than resource use. It is rather necessary to act toward an "absolute decoupling", meaning a growth of the activity volume and at the same time diminishing resource use, as it may be observed in Figure 1 [1]. 


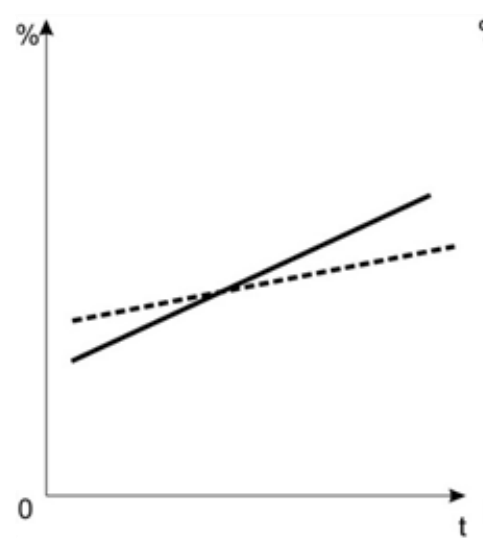

(a)

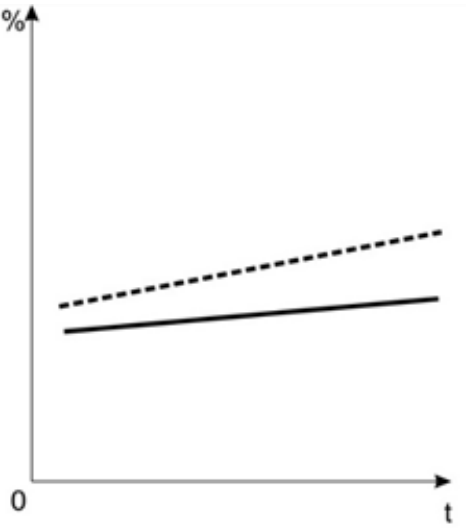

(b)

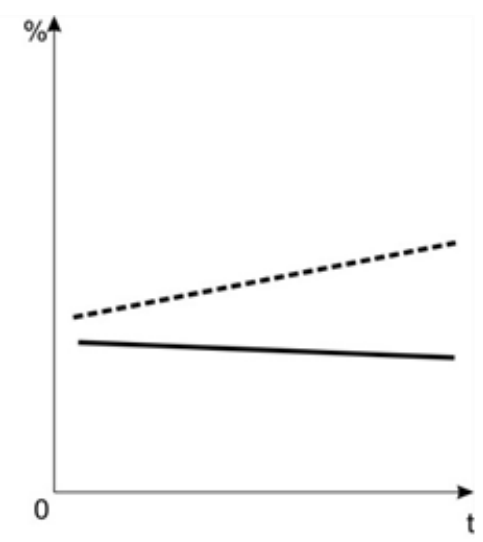

(c)

the rate of increase in resource consumption of restaurants in the touristic destination
the rate of increase in the activity volume of restaurants in the touristic destination

Figure 1. Models of resource use in a touristic destination: (a) the current situation; (b) the relative decoupling pattern; (c) the absolute decoupling pattern.

The subject of waste management in the restaurant industry falls into the promotion of pro-environmental consumption activity, which is, in general, more efficient when it is planned and implemented in a systematic manner and evaluated in a continuous manner [2-4].

To do so, it is a fundamental requisite to clearly understand what environmentally sustainable consumer behavior is, to know the theories that are effective for explaining the behavior, to recognize the factors that trigger it, and to know contemporary tourism and hospitality studies dealing with the behavior, which were not wholly uncovered in the existent literature.

Han, in his paper [5], also signified the importance of pro-environmental consumption activity. He (1) provided the conceptualization of environmentally sustainable consumer behavior, (2) presented a thorough review on social psychology and environmental psychology theories, (3) provided the discussion on key drivers of environmentally sustainable consumer behavior, and (4) introduced new tourism and hospitality studies about sustainability and consumer behavior.

During the COVID-19 pandemic, as the hospitality industry attempts to move on the path of sustainable development, administrators need to expand their efforts for improving natural environmental orientation (NEO), market orientation, resource orientation, and brand orientation by new hospitality's strategies.

Chun-Yi Ho, in his survey-based paper [6], studied multiple elements for green marketing orientation formulas in the Taiwanese hospitality industry in the COVID-19 pandemic and validated important elements through multiple viewpoints via the means of an MCDM. A mixture of fuzzy theory, DEMATEL, and DANP methods was applied for the estimation of green marketing orientations based on dissimilar viewpoints of strategy. A flexible, practical, and useful model for determining the hierarchical determinants of a strategic orientation program for the hospitality industry was proposed. These elements were ordered through the fuzzy DEMATEL and fuzzy DANP approaches.

\subsection{Waste Management in the Restaurant Industry}

The aim of this paper is to study another important group of policies in the public food area that aims to distance itself from the model of linear production ("supply with raw food materials, preparation of food dishes, consumption of food dishes, wastes evacuations") towards a circular model that extracts the maximum value from food resources and keeps them within the restaurant operational frame, or transfers them toward other economic 
agents for whom restaurant wastes are useful goods or raw materials (circular economy, i.e., zero wastes), as it can be observed in Figure 2 [1,7-9].

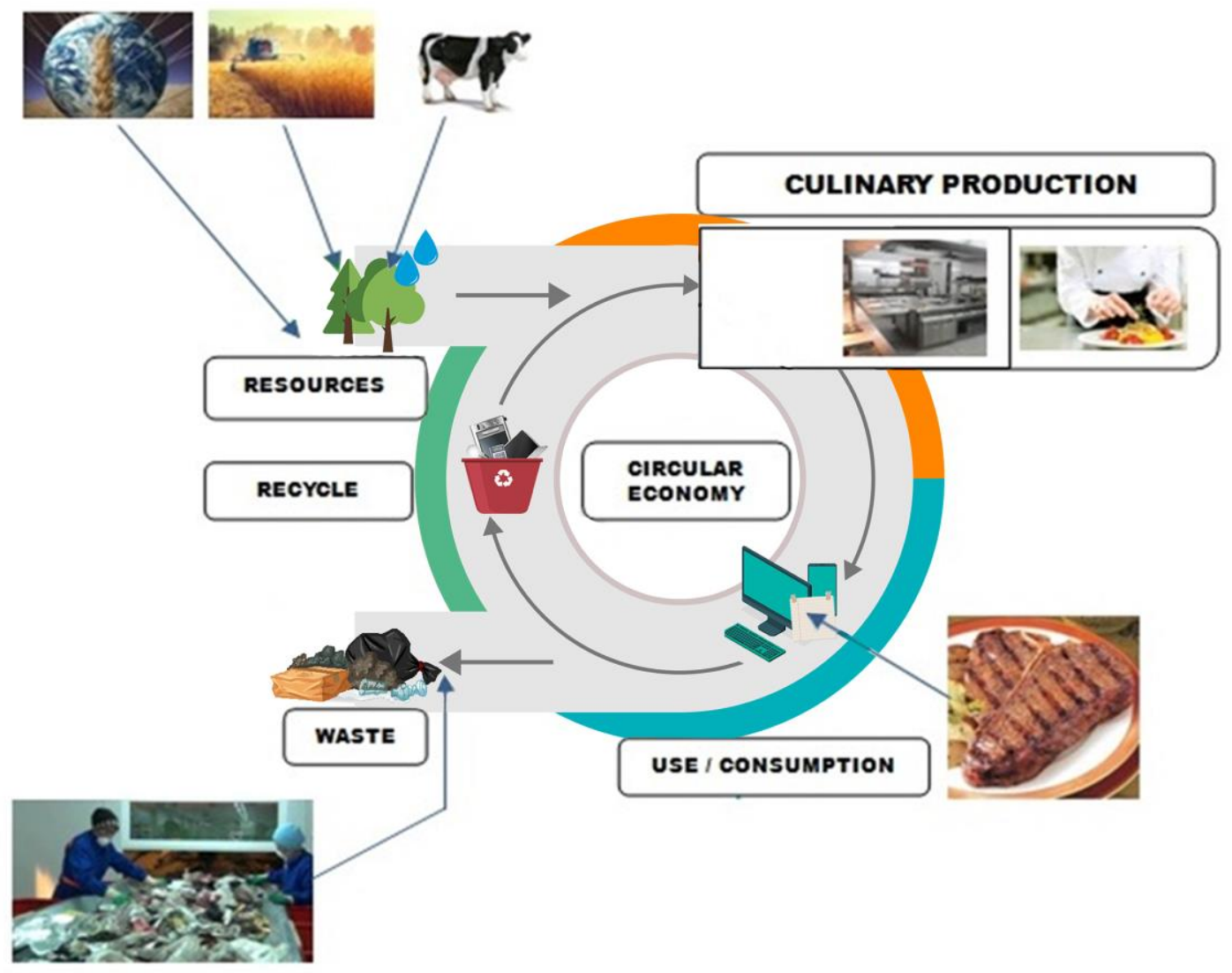

Figure 2. Diagram of circular economy in restaurants.

The concept involves changes in the whole ensemble of logistic chains, including the creation of food items, the operation models from the restaurant industry, the influence on client consumption choice by the menu list, as well as waste prevention and management $[10,11]$.

Bartłomiej emphasizes in his paper [12] the need for organizational improvements leading to the decrease of food waste and costs in restaurants. While the literature does report applications of lean management in service businesses, the literature contains few works on specific applications in the domain of food services [13-15]. Lean management was found to be useful in three study cases from Poland to decrease food waste and reduce operational costs. The case studies suggest a set of activities for organizations delivering food services to streamline their processes by applying lean management practices [16-19].

Carlos Martin shows, in his paper [20], that wasting food means missing opportunities to feed 820 million people who are undernourished (according to UNO, in 2018) and consuming scarce resources, such as land, water, and energy used for the production, processing, and distribution of food [21]. Firms in HORECA (hospitality, restaurant, and catering) represent a considerable share of total food waste and, more importantly, are characterized by an overall low sense of awareness about the sustainability-oriented innovation opportunities and challenges of minimizing food waste [22-26]. The article presents a series of case studies to explore the use of technological advancements in the downstream value chain [27-32]. A case study draws on a tech startup providing services for HORECA companies to address a new way for companies to solve the food waste challenge. Adopting technological innovations to quantify and minimize wastage via collaborations with third-party companies can be a strategic and cost-effective way to supplement a company's open innovation activities. Tehrani, in his paper [33], studied 
many restaurant activity cases, including the ones from Taiwan, and found that the most important factors essential for environment impact saving were: equipment/technology the ease of implementation of green practices, the efficient use of resources, and the personal values of customers.

Other studies concluded that the cost of implementation of green operations in restaurants can be recovered by better economic performance of the restaurants.

Summarizing the research in this area, the most significant impediments to improving sustainability in the restaurant industry are: lack of adequate knowledge and information on the side of both restaurant owners/managers and customers, the nature of the restaurant industry, regular customers and tourists that can impact the increase of food wastes in restaurants, lack of appropriate knowledge and technology in dealing with eco-waste management, design of the menus, and complexity in operations of a restaurant $[3,6,11,15,33]$.

It must be mentioned that the exact definition of physical waste is important as it constitutes the basis of state legal regulations referring to waste manipulation, processing, transportation, and elimination. Waste is a complex, subjective, and often controversial concept. Common people, business communities, politicians, or environment militants have different approaches, which explains the difficulty of getting comparable data concerning wastes from an organization to another or from a country to another.

Among the most frequent acceptations of the "waste" concept there are [34,35]:

- The EU Directives define waste as "any substance or object ... which the holder gives up or intends or is required to discard".

- The Basel Convention of the Program for Environment of UNO offers the following definition: "wastes are substances or objects which are disposed of or are intended to be disposed of or are required to be disposed of by the provisions of national law".

- In the system of limited resource production, waste is made of resources consumed in any other aim than the one to create added value [36].

- Resolutions of the Justice European Court have considered that the result of economic activity may be at the same time waste or product or a good or raw material or a substance, no matter its economic value [37].

In the context of the last presented acceptation, one may confirm that the waste concept is relative. A material becomes waste when it loses its primary function, but it may have a secondary function [38,39]. A material's failure from a certain productive context may become raw material in another context, which represents the basic principle of the circular economy [37]. Consider that, in this case, the waste concept should be related to the owner or the process and not to the object in itself.

It is also taken into consideration the hypothesis that effective waste management in restaurants may be restricted by barriers that depend on organizational and attitude factors rather than on the lack of capital availability, as well as on weak coordination between objectives concerning environment protection and operational functions of the management $[36,40]$.

In this context, the contribution and the main research objective of this paper are related to the optimization of production in restaurants based on the principles of the circular economy, by recycling waste. As a novelty, we mention the description of a multipurpose functional model of the supply chain in a restaurant, represented as interconnected processes covered by the flows of food and waste, with associated optimized cost flows. Reference is made to the applications of the model in sustainable technology and proper waste management. The proposed model called TEWAMA-R (Multipurpose Model of Technology and Waste Management in Restaurants) can be used as a tool to optimize waste management in a restaurant, having as a basic element the analysis of the causes of waste release.

The paper provides specific aspects of operational management regarding the logistic chain in hospitality, more specifically, in restaurant waste management, thus covering particular gaps in specialized literature [41-43]. 
After the literature study, the paper presents the functional modeling research methodology that was applied to the case study of a restaurant from a touristic destination in Brașov. The results chapter describes the technological process in the restaurant industry, the polyvalent functional model of waste management in the restaurant logistic chain, and the quantitative and value evaluation of waste from the technological processing of beef steak. The paper closes with the chapter of conclusions, which shows the benefits, limitations, and future directions.

\section{Materials and Methods}

The method used for the analysis of waste release and management processes is the functional modeling method. Functional analysis is a method of researching the functions of a product. The functions are identified by specific methods of analysis. The ordering aims at classification according to a functional logic and the establishment of interdependence relations. Hierarchy allows the evaluation of the order of importance of the functions. The researchers described a functional model of a supply chain for waste management, recovery, and reuse of plastic tableware. In the next section, the Hicks model for analyzing cyclical fluctuations was adapted to the flow of food in restaurants, waste, and accumulated costs. Methodologically, a series of logical scheme models were also considered, namely data flow diagrams (DFD) that allow one to model the flow of a process or information system and to be able to represent it in a coherent and intelligible visual form. Technological and managerial flow models were also used.

The research methodology includes the next steps: definition of the polyvalent model by describing the technologic process in the restaurant industry, setup of the polyvalent functional model of waste management on restaurant logistic chain, case study on the logistic chain of a restaurant in a Brassov, Romania touristic destination (as a classic example of the specific menu: beef steak with vegetables).

\section{Results and Discussions}

In the restaurant industry, food production is carried out based on clients' orders, the accepted term being "production-to-order" but orders may be honored within a period of time not affecting the clients' favorable perception, only on the condition of prior semi preparation, that is, "production-to-stock". The combination of these two production systems (to order, to stock) is necessary. It is essential to determine an estimated level of the demand for a day, for a certain event, or during well-defined periods of administration, for example, a week, a month, a quarter, a season, or a year.

Restaurant operators tend to substantiate the production level on overestimated request levels because clients' dissatisfaction has in fact much more serious consequences than the value of the wastes that may result from a demand lesser than the forecast. Generally, restaurants face a volatile demand, especially in the case of touristic destinations. In order to assure a capacity for acceptable response in case of demand variations and in order to reduce the work volume from their own kitchens, restaurant operators are drawn to modern possibilities of preserving raw food materials for longer periods of time (supplies in frozen state, portioning and vacuum, comfort products that food industry may deliver in very short delay). However, this comes at the risk of amplifying waste quantities generated by their own processes of culinary production, as well as by production processes of economic agents upstream the logistic chain.

\subsection{Definition of the Polyvalent Model by Describing the Technologic Process in the Restaurant Industry}

The activity from this area consists of combining the preparation and presentation operations of the culinary variety, confectionary-pastry preparations, and drinks with specific services determined by their serving and consumption in a harmonious ensemble. In culinary technology, transforming raw food material into finite or semi-finite products is achieved through a series of operations whose succession materializes the technological schema. 
In order to constitute the proposed model, restaurant operations were taken into consideration, that, by the nature of their function, may be: $A_{1}-$ Mechanic operationsoperations that do not determine the change in the initial state of the raw material (storage, measurement, dosage, transportation); $\mathrm{A}_{2}$-Physical operations-operations that determine the change in the physical state of raw material (physical operations without heat change: selection, grinding, mincing, decantation, sifting; physical operations with heat change: vaporization, baking, heating; physical operations with substance change: extraction, diffusion, frying); $\mathrm{A}_{3}$-Chemical operations; and $\mathrm{A}_{4}$ - Biochemical operations, in which substance transformations take place (maturing, coagulation, fermentation).

The ordered operations ensembles (for example $A_{1}+A_{2}+A_{3}+A_{4}$ ), by which the fabrication of preparations is achieved, constitute the technologic processes, on principle, taking place in the restaurant sector, which impose the following characteristics on the polyvalent model:

- $\quad$ Reduced degree of mechanization and automation;

- Small serial production or unique preparations;

- Varied sort structure, with relatively frequent modifications;

- Daily production from necessary raw material supply step;

- Production processes with minimal stocks of raw food materials, due to their perishable characteristics;

- Short period of achievement of every operation in the culinary production process.

Handling technological processes involves knowing the quantities of the necessary raw materials, all the transformations that appear in the applied processes, and the quantities of the finite products that result from processing. A shelf life is associated with the stock of food products, that is, a period of time in which they comply with the food safety conditions, after which depreciation occurs, causing food waste. It will be considered that all technological processes produce profound transformations of the processed raw materials, accompanied by quantitative losses due to: (a) elimination of the uneatable parts by preliminary operations, (b) physical processes of desiccation or evaporation, and (c) chemical transformations. All resulted modifications through technological processes determine normal losses whose value must be well known so that such a process may be correctly handled.

From the order of operations and dynamics of transformations, there appear significant waste quantities. Thus the restaurant operators are confronted with supplementary costs due to the depreciation of food products for which the demand was less than what was estimated. In addition, there are supplementary costs associated with recycling or waste disposal.

\subsection{Polyvalent Functional Model of Waste Management on Restaurant Logistic Chain}

A large contribution to the financial sustainability of a restaurant depends on the manager's ability to minimize wastes and use resources as efficiently as possible. This refers not only to food and drinks but also to work resources, consumed energy, and other operational expenses. When costs are kept under control, the restaurant has two alternatives: (1) to offer its preparations and services at a lesser price than those on the local market, that is, to assure a more favorable proportion of quality/prices to its client or (2) to get a higher volume of the commercial addition than its competitors, if the manager decides to sell at market price. Not all operators are aware of the waste volume from restaurant activity hence they do not see the necessity to watch the costs.

A restaurant activity may be described as a logistic chain in which raw food materials are transformed into a culinary preparation through a series of processes with sequential ongoings. Processes add value and create, at the same time, physical and non-physical wastes. Even operations between processes may lead to waste creation.

With every stage of food processing in a restaurant, there are associated identified wastes based on the "waste hierarchy" concept, described in Figure 3. 


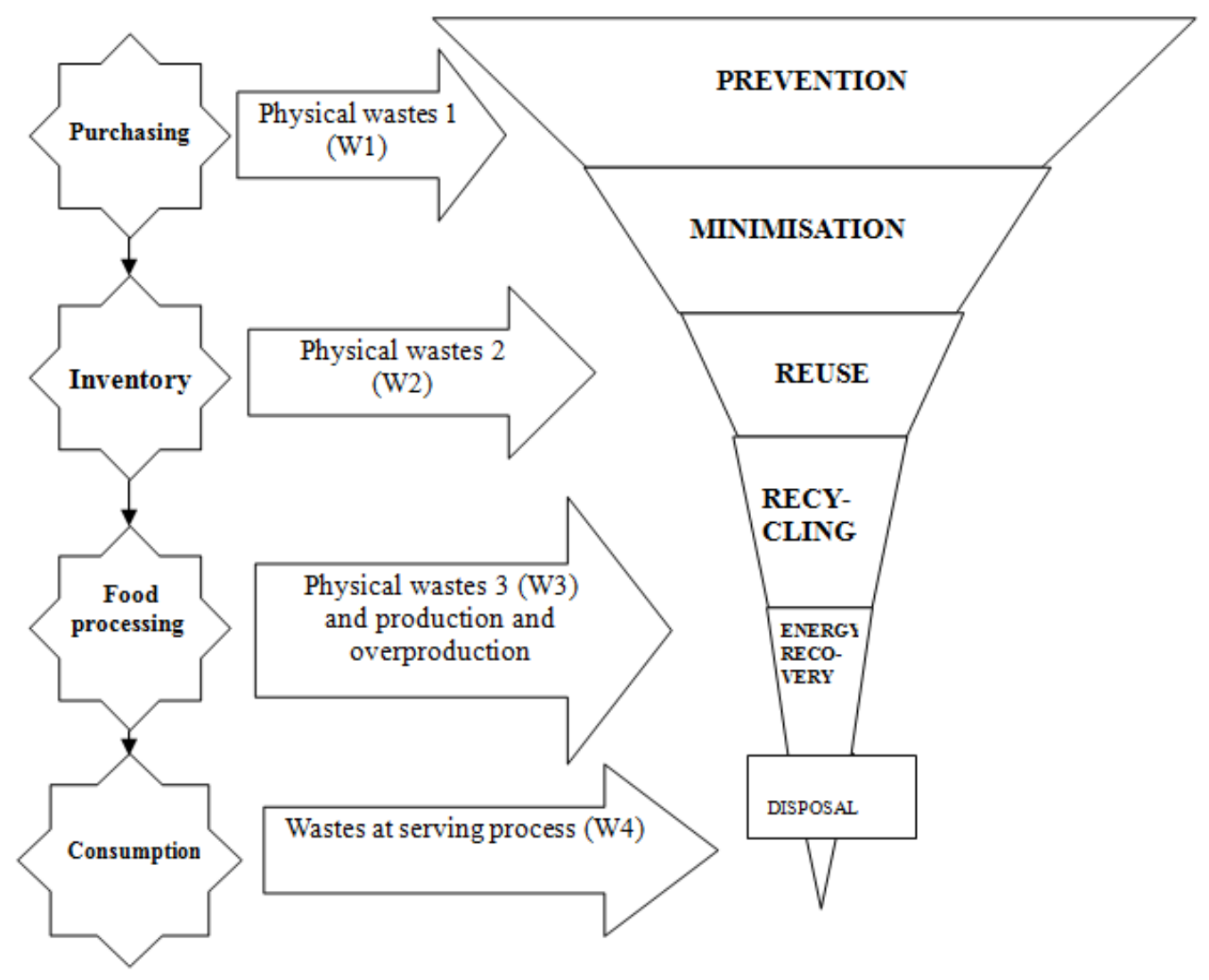

Figure 3. Causes of waste apparition in the process of aliment processing in restaurants and their treatment.

A compulsory element in waste management in restaurants is the application of the principles and rules linked to the "design hygienic" concept that completes the Polyvalent model of sustainable technology and waste management in restaurants (TEWAMA-R).

Beyond the concepts and principles presented as the defining elements of the polyvalent model from this study, reality shows us that wastes are not always visible with the naked eye. Registration and analyses are necessary in order to observe the waste quantity in the flow. In the absence of controls to observe variations and with the insufficiency of the use of certain resources, managers are exposed to losses, which makes it opportune to elaborate on models and corresponding costs.

Figure 3 shows, schematically, the phases of waste appearance in the technological and managerial flow of restaurant activity.

W1 - materials of organic nature/wrapping and others.; W2-prejudice due to defective manipulation/contamination at defective depositing/errors in demand estimation/overtaking the preservation delays; W3-production wastes due to technological losses/material wastes by contaminations or trash preparations/overproduction wastes due to errors of culinary production programming or errors of communication with organizational clients; W4-wastes in the serving process due to contaminations/client refusals/late cancellation of programmed events.

System variables relevant to this problem were taken into consideration; these are elements that become a simplified representation of the system. References were made to the technological process of complex aliment preparation (dishes), with quantitative and value evaluation of the wastes resulting from 5 technological stages (Stage $=$ stage; $\mathrm{Op}=\mathrm{op}-$ erations), respectively: (Stage1) Op.1-reception/Op.2-primary processing; (Stage 2) Op.3—freezing/Op.4—storage; (Stage 3) Op.5-de-freezing/Op.6-cooking; (Stage 4) Op.7-maintenance/Op.8 - assembling onto the plate; (Stage 5) Op.9—serving/Op.10clearing the table/Op.11—cashing. 
Consequently, the functions of the technological stages (Stage), the generation of wastes, as well as the operations (Op) of aliment transformation during the technologic flow, may be described by the polyvalent model of sustainable technology and waste management $(W)$ in restaurants (Figure 4 ).

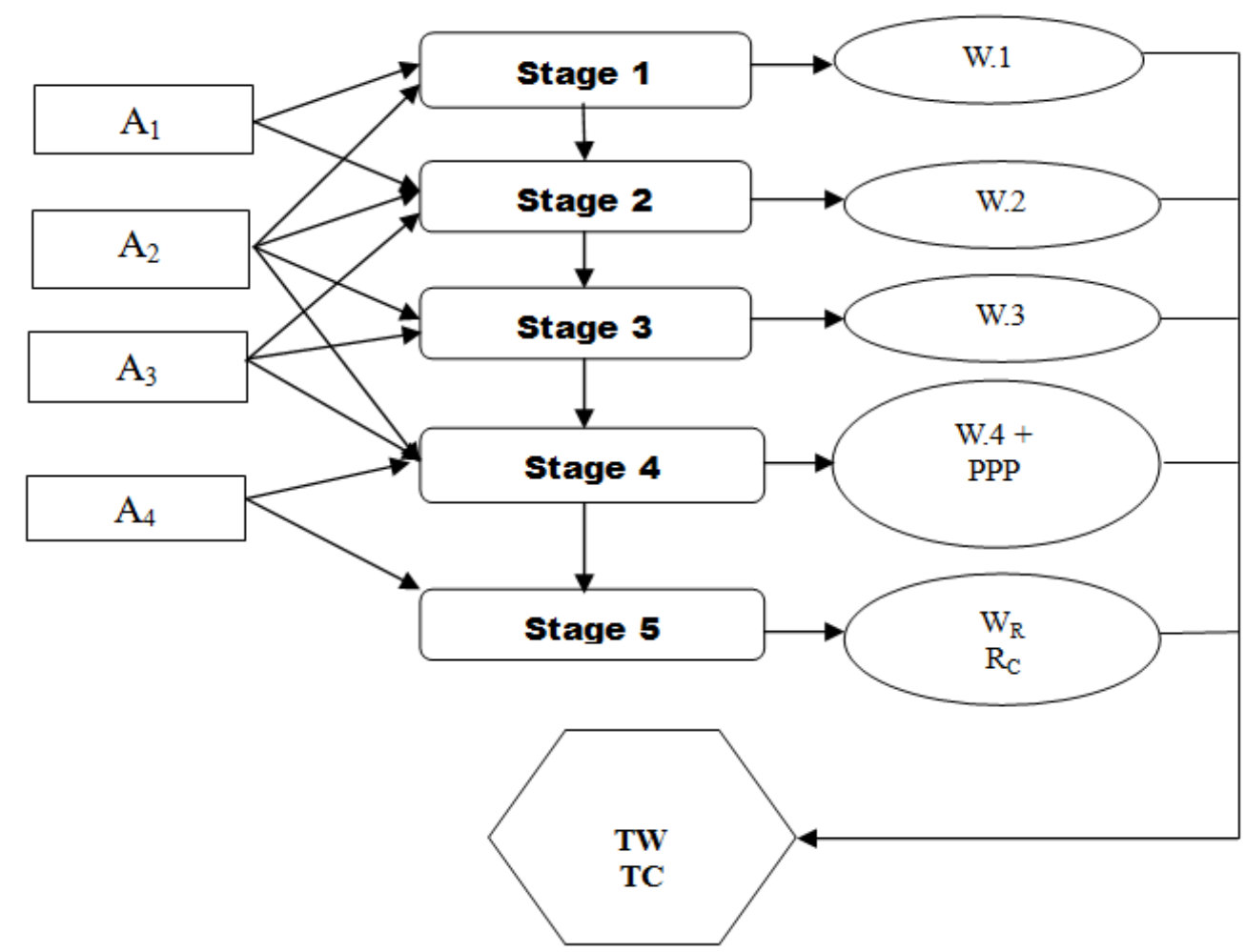

Figure 4. Diagram of the polyvalent model of waste technology and management in restaurants.

$\mathrm{A}_{1}$-mechanic operations; $\mathrm{A}_{2}$ - physical operations; $\mathrm{A}_{3}$-chemical operations; $\mathrm{A}_{4}-$ biochemical operations; Stage 1-reception and primary processing; Stage 2-freezing and storage; Stage 3-de-freezing and cooking; Stage 4-maintenance and assembling onto the plate (fr. montage); Stage 5-serving, clearing the table, pay; W.1, W.2, W.3, W.4-stage wastes in conformity with waste hierarchy; PPP-loss from food samples; $\mathrm{W}_{\mathrm{R}}$-waste from rejected dishes; $\mathrm{R}_{\mathrm{C}}$-consumption leftovers; TW—total wastes; $\mathrm{TC}$ - total costs. Complementarily with the technologic diagram, the cost control has the role of maximizing the profit and is linked to the technologists/operational managers' competence and, implicitly, to the used model. When cash flow is positive and the business is successful, cost control may seem unjustified. However, the high sales volume may hide a multitude of useless costs, which become evident only during periods with reduced sales that require the optimization of costs within the model. Therefore, a restaurant's operational success is not dependent on hazards but is the result of very accurate planning, which constitutes the application of a model, for example, a sustainable polyvalent one: technological/managerial/hygienic/design/economic.

3.3. Development and Application of a Polyvalent Model of Sustainable Technology and Waste Management, with Case Study on the Logistic Chain of a Restaurant in Brasov, Romania Touristic Destination

The case study refers to the classic example of a menu specific to a Brassov touristic destination, regarding the technologic process (emphasizing meat processing) of the preparation "beef steak with vegetables" (Table 1). 
Table 1. Quantitative and value initial evaluation of waste from the technological process of beef steak.

\begin{tabular}{|c|c|c|c|c|c|c|c|}
\hline Stage & Description & $\underset{\text { (kg) }}{\text { Quantity }}$ & $\begin{array}{c}\text { Market Price } \\
\text { (lei/kg) }\end{array}$ & $\begin{array}{c}\text { Quantity } \\
\text { Weight (\%) }\end{array}$ & $\begin{array}{c}\text { Market } \\
\text { Value (lei) }\end{array}$ & $\begin{array}{c}\text { Waste } \\
\text { Value (lei) }\end{array}$ & $\begin{array}{c}\text { Waste Cumulative } \\
\text { Value (lei) }\end{array}$ \\
\hline \multirow{3}{*}{$\begin{array}{l}\text { 1. Reception and } \\
\text { primary processing }\end{array}$} & Beef steak & 30.00 & 33.00 & 100.00 & 990.00 & - & - \\
\hline & Eatable quantity & 28.20 & 35.11 & 94.00 & 990.00 & - & - \\
\hline & Waste at Stage1 = W1 & -1.80 & 0.00 & -6.00 & 0.00 & -59.94 & -59.94 \\
\hline \multirow{2}{*}{ 2. Freezing and storage } & Quantity before Op.2 & 28.20 & 35.11 & 94.00 & 990.00 & - & - \\
\hline & Waste at Stage $2=\mathrm{W} 2$ & -0.60 & 0.00 & -2.00 & 0.00 & -21.24 & -81.18 \\
\hline \multirow{3}{*}{ 3. Defreezing and cooking } & Quantity before Stage3 & 27.60 & 35.87 & 92.00 & 990.00 & - & - \\
\hline & Loss by cooking $(20 \%)$ & -5.52 & 0.00 & -18.40 & 0.00 & . & - \\
\hline & Waste at Stage $3=\mathrm{W} 3$ & -0.16 & 0.00 & -0.53 & 0.00 & -5.79 & -86.97 \\
\hline \multirow{2}{*}{$\begin{array}{l}\text { 4. Maintenance and } \\
\text { assembling in plate }\end{array}$} & Net quantity in finite preparations & 21.92 & 45.16 & 37.07 & 990.00 & - & - \\
\hline & Loss from food samples (PPP) & -0.32 & 0.00 & -1.07 & 0.00 & -14.55 & -101.52 \\
\hline \multirow{2}{*}{$\begin{array}{l}\text { 5. Serving, clearing } \\
\text { and cashing }\end{array}$} & Waste from rejected dishes $\left(W_{R}\right)$ & -0.32 & 0.00 & -1.07 & 0.00 & -14.55 & -116.07 \\
\hline & Rests after consumption $\left(\mathrm{R}_{\mathrm{C}}\right)$ & 1.83 & 0.30 & 6.09 & 0.00 & -0.55 & -116.62 \\
\hline
\end{tabular}

Note: The acquisition total cost refers to useful quantity left after every stage, resulting in unitary expenses that must be retrieved by selling the beef steak after the prepared dish is served to the client.

The restaurant's internal logistic chain, presented in Figure 5, is divided into three departments: supply-storage (Stage 1 and 2), culinary preparation (Stage 3 and 4), and serving (Stage 5). The application of the functional model concentrated on physical waste, excluding non-physical waste because the restaurant managers refused the proposals to modify the production processes, arguing that they involve investment work, need a longer period of time, and disturb the existing flows whose performance level is accepted by the owners. Figure 4 presents the waste cumulative cost diagram, elaborated in conformity with the data calculated in Table 1 , where a value of waste quantity results after every stage (it is adjusted by dividing the 990 lei cost of beef steak supply by the eatable quantity left).
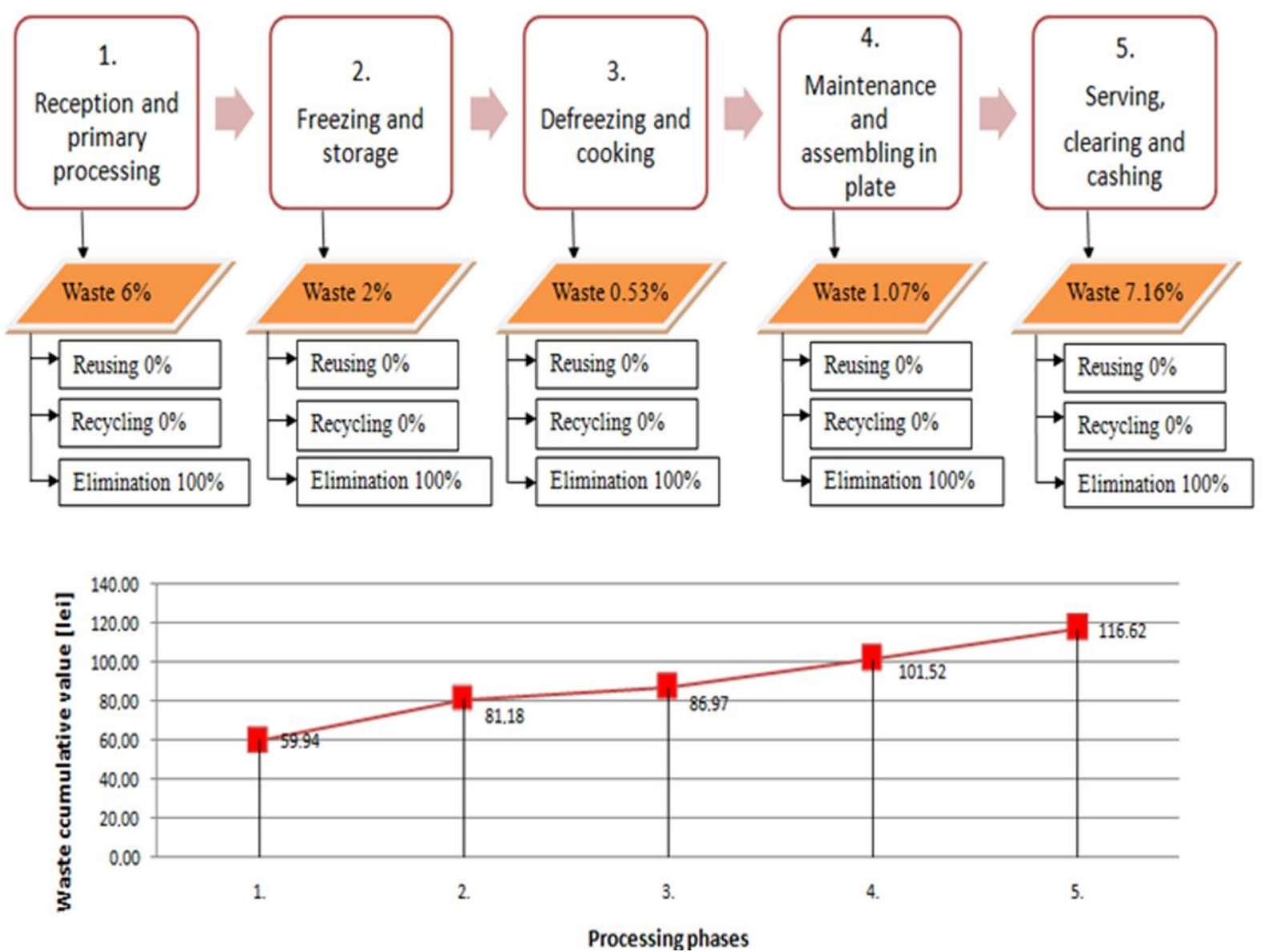

Figure 5. Waste value on restaurant logistic chain from the case study. 
An example calculation of the waste flow from every stage (identified on the basis of the waste hierarchy) within the model may be seen in the Box 1 below:

Box 1. Example of waste flow calculation from every stage.

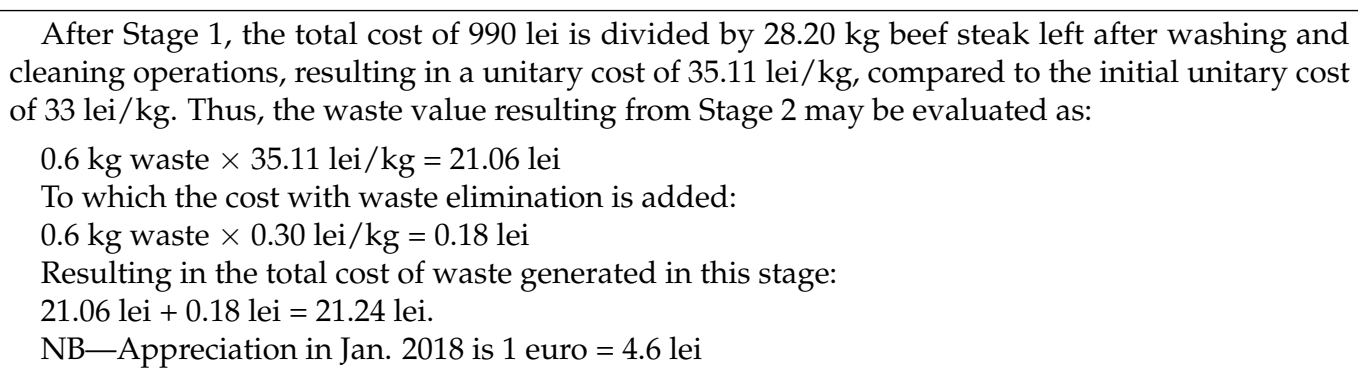

After the analyses of the logistic chain from Figure 5 it was observed that, by revising the specifications for the preparation of the "beef steak with vegetables", the rate of waste occurrence may be reduced and a part of the generated wastes may be reused or recycled. The new model of waste flow concerning the waste quantity and value is described in Table 2 and Figure 6.

Table 2. Quantitative and value evaluation of waste from the technological process of beef steak, after applying the principles of the waste management model (quantity per portion $=160 \mathrm{~g}$ ).

\begin{tabular}{|c|c|c|c|c|c|c|c|}
\hline Stage & Description & $\underset{\text { (kg) }}{\text { Quantity }}$ & $\underset{\text { (lei } / \text { kg) }}{\text { Market Price }}$ & $\begin{array}{c}\text { Quantity } \\
\text { Weight (\%) }\end{array}$ & $\begin{array}{c}\text { Market } \\
\text { Value (lei) }\end{array}$ & $\begin{array}{c}\text { Waste } \\
\text { Value (lei) }\end{array}$ & $\begin{array}{l}\text { Waste Cumulative } \\
\text { Value (lei) }\end{array}$ \\
\hline \multirow{5}{*}{$\begin{array}{l}\text { 1. Reception and } \\
\text { primary processing }\end{array}$} & Beef steak & 30.00 & 33.00 & 100.00 & 990.00 & - & - \\
\hline & Eatable quantity & 29.44 & 33.63 & 98.13 & 990.00 & - & - \\
\hline & Waste at Stage1 = W1 & -0.56 & 0.00 & -1.87 & 0.00 & -18.65 & -18.65 \\
\hline & Secondary product & & & & & & \\
\hline & $\begin{array}{l}\text { (steak extremities, rest of steak portioning, } \\
\text { work beef meat/hamburger) }\end{array}$ & 1.44 & - & 4.80 & 25.65 & -22.77 & - \\
\hline 2. Freezing and storage & $\begin{array}{l}\text { Quantity before Op.2 } \\
\text { Waste at Stage } 2=\mathrm{W} 2\end{array}$ & $\begin{array}{l}28.00 \\
-0.64\end{array}$ & $\begin{array}{l}36.27 \\
0.00\end{array}$ & $\begin{array}{l}93.33 \\
-2.13\end{array}$ & $\begin{array}{c}1015.65 \\
0.00\end{array}$ & -23.41 & -64.83 \\
\hline \multirow{3}{*}{$\begin{array}{l}\text { 3. Defreezing } \\
\text { and cooking }\end{array}$} & Quantity before Stage 3 & 27.36 & 37.12 & 91.20 & 1015.65 & - & - \\
\hline & Loss by cooking $(22 \%)$ & -5.98 & 0.00 & -19.93 & 0.00 & - & - \\
\hline & $\begin{array}{l}\text { Secondary product (work beef } \\
\text { meat/hamburger) }\end{array}$ & 0.13 & 10.00 & 0.43 & 1.28 & -3.47 & -68.30 \\
\hline \multirow{2}{*}{$\begin{array}{l}\text { 4. Maintenance and } \\
\text { assembling in plate }\end{array}$} & Net quantity in finite preparation & 21.25 & 47.85 & 70.85 & 1016.93 & , & - \\
\hline & Loss by food samples (PPP) & -025 & 0.00 & -0.83 & 0.00 & -12.04 & -80.34 \\
\hline \multirow{2}{*}{$\begin{array}{l}\text { 5. Serving, clearing } \\
\text { and cashing }\end{array}$} & Residue/Waste from rejected dishes $\left(\mathrm{W}_{\mathrm{R}}\right)$ & -0.25 & 0.00 & -0.83 & 0.00 & -0.00 & -80.34 \\
\hline & Rests after consumption $\left(\mathrm{R}_{\mathrm{C}}\right)$ & 1.43 & 0.00 & 4.76 & 0.00 & 0.00 & -80.34 \\
\hline
\end{tabular}

Comparing phase 1 (reception and primary processing) in Figures 5 and 6 it can be seen that revising the specifications for the preparation of the "beef steak with vegetables", leads to the generation of a larger amount of waste $(6.67 \%<6 \%)$, which is reused in the proportion of $72 \%$, eliminating only $28 \%$ of waste. This not only involves reducing the costs of purchasing raw materials for phase 2 of processing (freezing and storage), but also reducing the costs of waste management (a smaller amount of waste will be eliminated).

Another consequence of revising the specifications for the preparation is that in the third phase of processing (de-freezing and cooking) the amount of waste obtained $(0.43 \%)$ is reused in the proportion of $100 \%$. This element has beneficial effects such as the decrease in the purchase price of the input raw materials for phase 4 (maintenance and assembling in plate) and the complete elimination of the costs of waste management from phase 3.

There is also a reduction in the amounts of waste resulting from phase $4(0.83 \%<$ $1.07 \%)$ and phase $5(5.59 \%<7.16 \%)$.

The total quantity of beef meat waste after one month (30 days) of using the perfected technological process for the preparation of the "beef steak with vegetables" was $4.70 \mathrm{~kg}$, that is, $6.4 \%$ less than in the initial technological diagram. If in the initial variant, the whole meat waste quantity were to be eliminated at the municipality ecologic junkyard (through the local sanitation service), after applying the TEWAMA-R Model, the resulted 
beef meat waste quantity would valorized on each of the 4 steps of the waste hierarchy taken into consideration:

- $\quad$ First step of hierarchy/prevention: $400 \mathrm{~g}$

- Second step/reuse: $1440 \mathrm{~g}+130 \mathrm{~g}=1570 \mathrm{~g}(33.4 \%)$

- Third step/recycling: $250 \mathrm{~g}+250 \mathrm{~g}+1430 \mathrm{~g}=1930 \mathrm{~g}(41.1 \%)$

- Fourth step/elimination: $560 \mathrm{~g}+640 \mathrm{~g}=1200 \mathrm{~g}(25.5 \%)$

- Total beef meat waste (step $2+3+4)=4700 \mathrm{~g}(100.0 \%)$

The percentage of waste reused increased from $0 \%$ to $33.4 \%$, by identifying a secondary function for the waste resulted after cutting, de-freezing, and cooking operations. Recycling increased from $0 \%$ to $41.1 \%$ by introducing in the process certain simple technological operations. The remaining waste $(25.5 \%)$ could not be reused or recycled and was eliminated (by the sewage system or by depositing in ecologic junkyards). The reduction of the weight of evacuated waste is remarkable, from $100 \%$ to $25.5 \%$. Consequently, the waste elimination costs were significantly reduced and the restaurant social responsibility increased by developing new waste valorizing possibilities in secondary logistic chains.
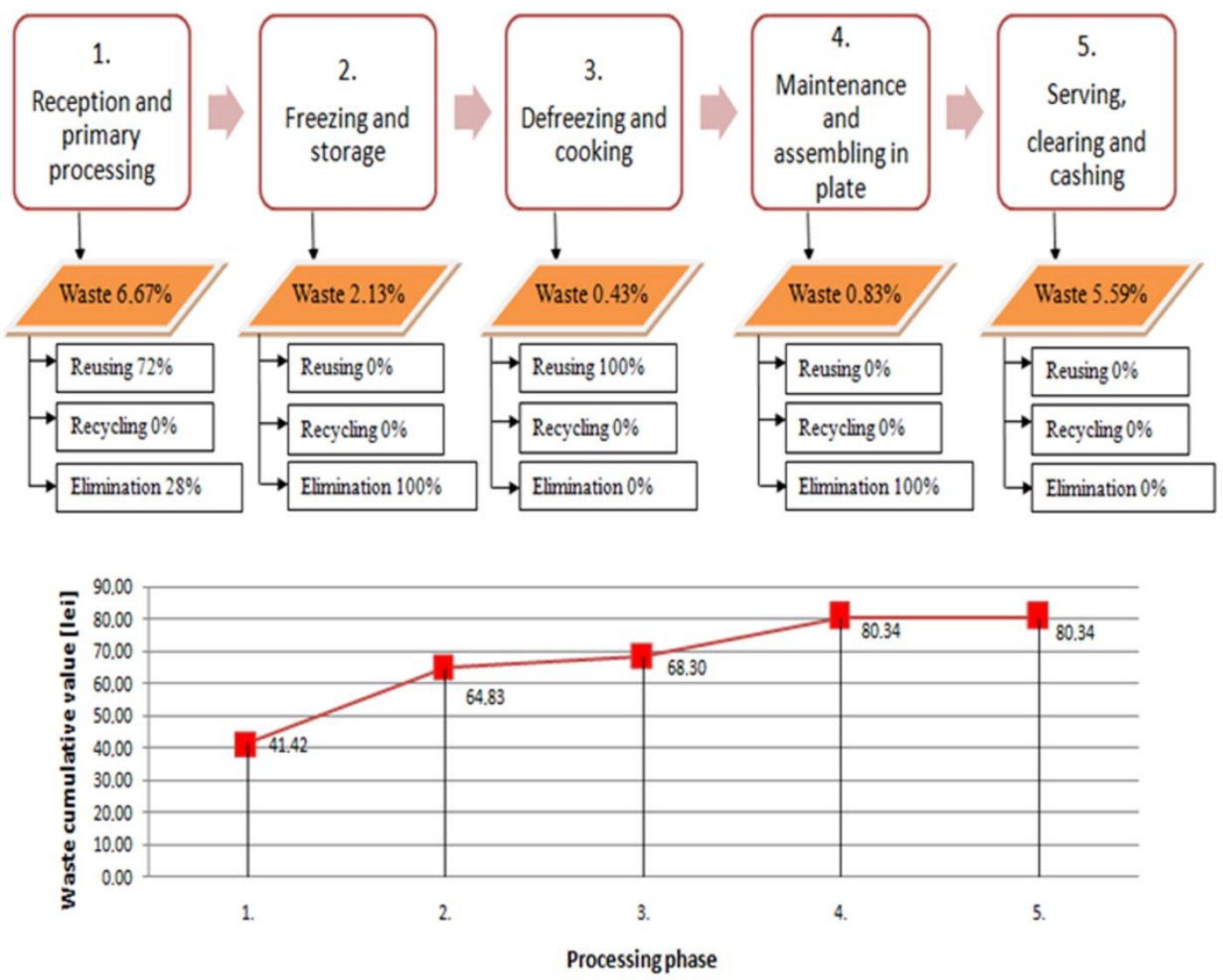

Figure 6. Waste value on restaurant logistic chain after applying the described model.

We may appreciate that, by modifying the menu list and adjusting the preparation technological card, that, by reducing the raw quantity of the steak portion from $200 \mathrm{~g}$ to $160 \mathrm{~g}$ the rests after the consumption of the finite preparation could be reduced from $1.83 \mathrm{~kg}$ to $1.43 \mathrm{~kg}$, and similarly with $400 \mathrm{~g}$. With the diminishing of the raw quantity, the net portion of beef steak from $160 \mathrm{~g}$ to $125 \mathrm{~g}$ determines the increase in the portion number from 137 to 170, which leads to an increase in the restaurant income flow by approximately $15 \%$. Confirming the hypothesis that, by diminishing the meat portion weight, the finite preparation selling price in the menu list is proportionally adjusted.

As it may be observed in Tables 1 and 2, compared to the standard technological process, after applying the proposed model, the cumulated value of the meat waste resulting 
in the case of the "beef steak with vegetables" preparation was reduced by $31 \%$, from 116.62 lei/month to 80.34 lei/month. A cost reduction of 36.28 lei/month by applying the TEWAMA-R Model may seem insignificant, but we only speak about a component of a single culinary preparation.

Activating secondary logistic chains, consisting of directing towards carnivorous feeding (fur animals, trout, zoological garden, shelters for stray dogs, etc.), leads to the diminishing of the eliminated waste through the sanitation firm with $1.67 \mathrm{~kg} / \mathrm{month}$. Even if the registered economy this way has a minor financial impact for each product, the perspective changes when all the recipe ingredients and all menus are taken into consideration, that is, in the lump monthly culinary production (all the culinary products made). If we generally take into account that the restaurant menu list includes approximately 50 culinary preparations, on average, one may appreciate that a cost reduction of 1800 lei/month, 21,600 lei/year, might be possible. This sum becomes important if it is directed towards wage funds, and there is great advantage in reducing the waste ecologic impact.

\section{Conclusions}

Restaurant food waste is substantial and largely avoidable, its identification demonstrating that it is present at every stage of the culinary technological process, even in intermediate operations. Functional modeling shows possibilities to minimize physical waste through the possibility of recycling it, either to be recovered as a raw material or to make a by-product, which can generate added value in the logistics chain of the restaurant.

By applying the analyzed multipurpose model, the waste stream that generates the highest costs is minimized and restaurants are more likely to improve their competitive position in terms of sustainability. Practically, waste losses are reduced, while complying with legal provisions on environmental protection.

The multipurpose model of technology and waste management in restaurants (TEWAMAR) becomes sustainable in the context in which the function of the technological stage ("Stage") of waste generators as well as the operation (Op) based on food processing along the technological flow, can be described by analyzing the quantities and costs of waste. The model can also be used to facilitate internal communication within the restaurant, with the external one, that is, with other organizations, in order to reduce the amount of waste.

In the application of the study, by revising the preparation specification of the preparation "roast beef with vegetables", the rate of waste may be reduced and some of the waste generated may be reused or recycled. By applying the TEWAMA-R model to this food preparation, the total amount of reused beef waste per month increased to $33.4 \%$ and the recycling of waste increased to $41.1 \%$ (given that all the waste was disposed of in the application of standard technology). Disposal was reduced from $100 \%$ to $25.5 \%$.

Statistically, these trends show by extrapolation the importance of applying such a model given that all the ingredients of the recipe and all menus are taken into account, that is, there is an integrated analysis of the restaurant's monthly culinary output, which quantifies production optimization based on circular economy.

On average, a restaurant produces 25,000 to 75,000 pounds of waste per year, from which only $14.3 \%$ of the leftover food is recycled, $1.4 \%$ donated, and the rest, $84.3 \%$ of such food, is discarded. The reduction of waste from the restaurant industry produces, besides the increase of the profit of the respective unit, also the increase of the sustainability indices for the respective business, major positive effects on the environment. Knowing the huge amount of natural resources consumed for the production of food raw materials (especially in terms of meat, dairy products, etc.) it can be seen that the model presented in the paper contributes primarily to reducing the consumption of fresh water, energy. At the same time, the impact on the environment is reduced by eliminating an important matrix of waste and by-products generated in the restaurant industry.

A limitation of the TEWAMA-R model is the complexity of the technological flow, the restaurant's monthly culinary output, recipes, and the ingredients used. Further case 
studies should be taken into consideration in order to establish the efficiency degree and to make fine adjustments in the model parameters.

Future research directions will use various techniques for Environmental Impact Assessment, and will consider assessing the impact of this method of reducing waste in the restaurant industry vis-à-vis the footprint of the public food business on the environment.

Author Contributions: Conceptualization, R.G. and G.-I.F.; methodology, R.G., G.-I.F. and L.G.; software, L.G., O.B.O.; validation, G.-I.F. and N.T.; formal analysis, L.G., O.B.O.; writing-original draft preparation, R.G. and G.-I.F.; writing—review and editing, R.G. and L.G.; supervision, R.G.; project administration, G.-I.F. and N.T.; funding acquisition, L.G. and O.B.O. All authors have read and agreed to the published version of the manuscript.

Funding: This research received no external funding.

Institutional Review Board Statement: Not applicable.

Informed Consent Statement: Not applicable.

Data Availability Statement: The data presented in the study are available on request from the corresponding author.

Acknowledgments: Authors wish to acknowledge the support of the Transilvania University of Brasov, Romania.

Conflicts of Interest: The authors declare no conflict of interest.

\section{References}

1. Bontoux, L.; Leone, F. The Legal Definition of Waste and Its Impact on Waste Management in Europe. In A Report Prepared by IPTS for the Committee for Environment, Public Health and Consumer Protection of the European Parliament; Isla de la Cartuja s/n E-41092 Sevilla Spain; European Commission: Brussels, Belgium, 1997; pp. 1-117.

2. Manosuthi, N.; Lee, J.; Han, H. Predicting the revisit intention of volunteer tourists using the merged model between the theory of planned behavior and norm activation model. J. Travel Tour. Mark. 2020, 37, 510-532. [CrossRef]

3. Steg, L.; Vlek, C. Encouraging pro-environmental behaviour: An integrative review and research agenda. J. Environ. Psychol. 2009, 29, 309-317. [CrossRef]

4. Untaru, E.; Ispas, A.; Candrea, A.N.; Luca, M.; Epuran, G. Predictors of individuals' intention to conserve water in a lodging context: The application of an extended theory of reasoned action. Int. J. Hosp. Manag. 2016, 59, 50-59. [CrossRef]

5. Han, H. Consumer behavior and environmental sustainability in tourism and hospitality: A review of theories, concepts and latest research. J. Sustain. Tour. 2021, 29, 1021-1042. [CrossRef]

6. Ho, C.Y.; Tsai, B.H.; Chen, C.-S.; Lu, M.-T. Exploring Green Marketing Orientations toward Sustainability the Hospitality Industry in the COVID-19 Pandemic. Sustainability 2021, 13, 4348. [CrossRef]

7. Simboli, A.; Taddeo, R.; Morgante, A. Value and Wastes in manufacturing. An Overview and a New Perspective Based on Eco-Efficiency. Adm. Sci. 2014, 4, 173. [CrossRef]

8. Hicks, C.; Heidrich, O.; McGovern, T.; Donnelly, T. A Functional Model of Supply Chains and waste. Int. J. Prod. Econ. 2004, 89, 165-174. [CrossRef]

9. Østergaard, S.; Hanssen, O.J. Wasting of Fresh-Packed Bread by Consumers-Influence of Shopping Behavior, Storing, Handling, and Consumer Preferences. Sustainability 2018, 10, 2251. [CrossRef]

10. Peira, G.; Bollani, L.; Giachino, C.; Bonadonna, A. The Management of Unsold Food in Outdoor Market Areas: Food Operators' Behaviour and Attitudes. Sustainability 2018, 10, 1180. [CrossRef]

11. Stöckli, S.; Dorn, M.; Liechti, S. Normative prompts reduce consumer food waste in restaurants. Waste Manag. 2018, 77, 532-536. [CrossRef]

12. Gladysz, B.; Buczacki, A.; Haskins, C. Lean Management Approach to Reduce Waste in HoReCa Food Services. Resources 2020, 9 , 144. [CrossRef]

13. Gunders, D.; Bloom, J. Wasted: How America is Losing up to 40 Percent of Its Food from Farm to Fork to Landfill; Natural Resources Defense Council: New York, NY, USA, 2017.

14. Papargyropoulou, E.; Lozano, R.; Steinberger, J.K.; Wright, N.; Ujang, Z. The food waste hierarchy as a framework for the management of food surplus and food waste. J. Clean. Prod. 2014, 76, 106-115. [CrossRef]

15. Blum, D. Ways to Reduce Restaurant Industry FoodWaste Costs. Int. J. Appl. 2020, 19, 1-12.

16. Pirani, S.I.; Arafat, H.A. Reduction of food waste generation in the hospitality industry. J. Clean. Prod. 2016, 132, 129-145. [CrossRef]

17. Tsai, W.-T. Turning Food Waste into Value-Added Resources: Current Status and Regulatory Promotion in Taiwan. Resources 2020, 9, 53. [CrossRef] 
18. Sakaguchi, L.; Pak, N.; Potts, M.D. Tackling the issue of food waste in restaurants: Options for measurement method, reduction and behavioral change. J. Clean. Prod. 2018, 180, 430-436. [CrossRef]

19. Abdelhadi, A. Using lean manufacturing as service quality benchmark evaluation measure. Int. J. Lean Six Sigma 2016, 7, 25-34. [CrossRef]

20. Martin-Rios, C.; Hofmann, A.; Mackenzie, N. Sustainability-Oriented Innovations in Food Waste Management Technology. Sustainability 2021, 13, 210. [CrossRef]

21. Read, Q.D.; Brown, S.; Cuéllar, A.D.; Finn, S.M.; Gephart, J.A.; Marston, L.T.; Meyer, E.; Weitz, K.A.; Muth, M.K. Assessing the environmental impacts of halving food loss and waste along the food supply chain. Sci. Total Environ. 2020, 712, 136255. [CrossRef]

22. Poore, J.; Nemecek, T. Reducing food's environmental impacts through producers and consumers. Science 2018, 360, 987-992. [CrossRef]

23. Stenmarck, Â.; Jensen, C.; Quested, T.; Moates, G.; Buksti, M.; Cseh, B.; Juul, S.; Parry, A.; Politano, A.; Redlingshofer, B. Estimates of European Food Waste Levels; IVL Swedish Environmental Research Institute: Stockholm, Sweden, 2016.

24. Martín-Rios, C.; Ciobanu, T. Hospitality innovation strategies: An analysis of success factors and challenges. Tour. Manag. 2019, 70, 218-229. [CrossRef]

25. Martin-Rios, C.; Demen-Meier, C.; Gössling, S.; Cornuz, C. Food waste management innovations in the foodservice industry. Waste Manag. 2018, 79, 196-206. [CrossRef] [PubMed]

26. Filimonau, V.; Delysia, A. Food waste management in hospitality operations: A critical review. Tour. Manag. 2019, 71, 234-245. [CrossRef]

27. Klewitz, J.; Hansen, E.G. Sustainability-oriented innovation of SMEs: A systematic review. J. Clean. Prod. 2014, 65, 57-75. [CrossRef]

28. Silvennoinen, K.; Nisonen, S.; Pietiläinen, O. Food waste case study and monitoring developing in Finnish food services. Waste Manag. 2019, 97, 97-104. [CrossRef]

29. Filimonau, V.; Matute, J.; Kubal-Czerwińska, M.; Krzesiwo, K.; Mika, M. The determinants of consumer engagement in restaurant food waste mitigation in Poland: An exploratory study. J. Clean. Prod. 2020, 247, 119105. [CrossRef]

30. Leverenz, D.; Hafner, G.; Moussawel, S.; Kranert, M.; Goossens, Y.; Schmidt, T. Reducing food waste in hotel kitchens based on self-reported data. Ind. Mark. Manag. 2020, in press. [CrossRef]

31. Martin-Rios, C.; Zizka, L.; Varga, P.; Pasamar, S. KITRO: Technology solutions to reduce food waste in Asia-Pacific hospitality and restaurants. Asia Pac. J. Tour. Res. 2020, 25, 1-8. [CrossRef]

32. Audet, R.; Brisebois, É. The social production of food waste at the retail-consumption interface. Sustainability 2019, $11,3834$. [CrossRef]

33. Tehrani, M.; Fulton, L.; Schmutz, B. Green Cities and Waste Management: The Restaurant Industry. Sustainability 2020, $12,5964$. [CrossRef]

34. Parfitt, J.; Barthel, M.; Macnaughton, S. Food waste within food supply chains: Quantification and potential for change to 2050. Philos. Trans. R. Soc. B 2010, 365, 3065-3081. [CrossRef] [PubMed]

35. Okawa, K. Market and Trade Impacts of Food Loss and Waste Reduction. In OECD Food, Agriculture and Fisheries Papers; OECD Publishing: Paris, France, 2015; p. 75. [CrossRef]

36. Cicatiello, C.; Franco, S.; Pancino, B.; Blasi, E. The value of food waste: An exploratory study on retailing. J. Retail. Consum. Serv. 2016, 30, 96-104. [CrossRef]

37. Thyberg, K.L.; Tonjes, D.J. Drivers of food waste and their implications for sustainable policy development. Resour. Conserv. Recycl. 2016, 106, 110-123. [CrossRef]

38. Hebrok, M.; Boks, C. Household food waste: Drivers and potential intervention points for design-An extensive review. J. Clean. Prod. 2017, 151, 380-392. [CrossRef]

39. Koivupuro, H.-K.; Hartikainen, H.; Silvernoinen, K.; Katajajuuri, J.-M.; Heikintalo, N.; Reinikainen, A.; Jalkanen, L. Influence of socio-demographical, behavioural, and attitudinal factors on the amount of avoidable food waste generated in the Finnish household. Int. J. Consum. Stud. 2012, 36, 183-191. [CrossRef]

40. Kristina, S.; Wijaya, B.M. Risk management for food and beverage industry using Australia/New Zealand 4360 Standard. IOP Conf. Series. Mater. Sci. Eng. 2017, 277, 1-11. [CrossRef]

41. Gruia, R. Evolutia Stiintifica a Gastronomiei in Cadrul Actului Alimentar; Clarion: Brasov, Romania, 2018; pp. 49-68.

42. Gruia, R. Gatronomia si Principiile Biologiei Alimentatiei; Clarion: Brasov, Romania, 2018; pp. $23-37$.

43. Mourad, M. Recycling, recovering and preventing "food waste": Competing solutions for food systems sustainability in the United States and France. J. Clean. Prod. 2016, 126. [CrossRef] 